\title{
The relationship of obstructive sleep apnea risk with the disease severity and clinical parameters in COPD population
}

\author{
๑DAli Onur Keleş ${ }^{1}$, @Sezgi Şahin Duyar ${ }^{1}$, @Funda Aksu², @Selma Fırat ${ }^{2}$ \\ ${ }^{1}$ University of Health Sciences, Atatürk Chest Diseases and Thoracic Surgery Training and Research Hospital, Department of Pulmonology, Ankara, Turkey \\ ${ }^{2}$ University of Health Sciences, Atatürk Chest Diseases and Thoracic Surgery Training and Research Hospital, Sleep Disorders Center, Ankara, Turkey
}

Cite this article as: Keleş AO, Şahin Duyar S, Aksu F, Fırat S. The relationship of obstructive sleep apnea risk with the disease severity and clinical parameters in COPD population. J Health Sci Med 2022; 5(1): 67-72.

\begin{abstract}
Aim: Obstructive sleep apnea syndrome (OSAS) and chronic obstructive pulmonary disease (COPD) have common pathophysiological mechanisms affecting the prognosis of each other. This study aims to investigate the relationship between the presence of OSA risk and the severity of COPD and to determine the possible clinical features for OSA risk for COPD patients.

Material and Method: The patients $(\mathrm{n}=181)$ who applied to the outpatient clinics of pulmonology between September - November 2019 with the diagnosis of COPD, were analyzed cross-sectionally. Demographic features, anthropometric measurements, comorbidities, smoking status, and severity of dyspnea, respiratory functions, and exacerbation frequency in the last year were evaluated. All patients were questioned with the Epworth sleepiness scale (ESS) for detecting excessive daytime sleepiness (EDS), and the STOP-Bang for determining the risk of OSA.

Results: The rate of diabetes, waist and hip circumference measurements, median ESS score, and EDS ratio were found to be higher in patients with moderate/high OSA risk when compared to patients with low OSA risk. In the multivariate regression model; lower oxygen saturation (OR: $0.83 ; \mathrm{p}=0.007)$ and higher ESS score $(\mathrm{OR}=1.28 ; \mathrm{p}<0.001)$ were determined as independent risk factors affecting the OSA risk to be moderate/high.

Conclusion: Low oxygen saturation, accompanying diabetes, high ESS score and, high waist-hip circumference stand out as useful factors in determining OSA risk in the COPD population. However, OSA risk was found to be the same among all COPD stages. We suggest that all COPD patients should be questioned for OSA risk regardless of the stage.
\end{abstract}

Keywords: Obstructive sleep apnea syndrome (OSAS), chronic obstructive pulmonary disease (COPD), Epworth sleepiness scale (ESS), STOP-Bang survey

\section{INTRODUCTION}

It is known that chronic obstructive pulmonary disease (COPD) has many comorbidities affecting prognosis. Obstructive sleep apnea syndrome (OSAS) which is one of the common comorbidities, is affected by various clinical and pathophysiological factors associated with COPD. According to epidemiologic studies, OSA can be present in about 10 to $15 \%$ of patients with COPD $(1,2)$. Hypoxemia and inflammation are the main factors affecting the pathology and prognosis of both diseases. The overlap of OSA and COPD results in more profound nocturnal hypoxemia especially during rapid eye movement (REM) sleep and cardiovascular comorbidities $(3,4)$.

Peripheral fluid retention shifting rostral during sleep, corticosteroid therapy which may weaken pharyngeal muscles and cigarette smoking causing inflammation in the upper airway, facilitate the collapsibility of the upper airway in COPD (3). A phenotypic tendency for the coexistence of OSA was observed for the patients with chronic bronchitis while hyperinflation associated with COPD was found to be protective against upper airway collapse in the predominant emphysema phenotype (57). Besides, cachexia which is seen during the end stages of COPD might decrease the likelihood of coexisting OSA in this population. The alterations in pathophysiological changes in the stages and phenotypes of COPD can affect the prevalence of OSA. Furthermore, OSA has a significant effect on the survival of COPD patients. It may increase the lower airway inflammation and worsen respiratory failure in COPD (1). In some studies, it is associated with daytime oxygen desaturation, hypercapnia, and poor quality of life in patients with COPD $(2,8,9)$. 
Screening for OSA risk is an important part of the clinical evaluation of patients with COPD. This study was conducted to find the relationship between the presence of obstructive sleep apnea (OSA) risk and the severity of COPD and to reveal the clinical findings which can determine the intermediate/high OSA risk in COPD patients.

\section{MATERIAL AND METHOD}

The study was approved by the Keçiören Training and Research Hospital Clinical Research Ethics Committee (Date: 11.09.2019, Decision No:2012-KAEK-15/1938). All procedures were carried out in accordance with the ethical rules and the principles of the Declaration of Helsinki.

\section{Patients}

In this study; 181 patients aged between $40-75$ years, who were admitted to the outpatient clinics of pulmonology between September 1 1st and November 31 st, 2019 with the diagnosis of COPD, were analyzed cross-sectionally. Only the patients who signed informed consent were enrolled in the study. Patients with congestive heart failure, chronic renal disease, psychiatric or neurological diseases, shift work, and patients on positive airway pressure treatment due to respiratory failure were excluded.

The diagnosis of COPD and the evaluation of disease severity was based on the global initiative for chronic obstructive lung disease (GOLD) 2019 criteria (10). Combined COPD assessment including symptom severity and exacerbation history was used.

\section{Measurements}

Demographic features [age, gender], anthropometric measurements, comorbidities, smoking status, and severity of dyspnea according to the modified medical research council (mMRC) scale (11), respiratory functions, and exacerbation frequency in the last year were evaluated.

For anthropometric evaluation height $[\mathrm{m}]$, weight $[\mathrm{kg}]$, neck, waist, and hip circumferences $(\mathrm{cm})$ were measured with a tape measure. Weight was measured with light clothing and without shoes. The height was measured on bare feet with the thin rod parallel to the floor that touched the head during deep inspiration while standing upright. The body-mass index (BMI) was calculated as weight $[\mathrm{kg}]$ divided by the square of height $\left[\mathrm{m}^{2}\right]$. Neck circumference (NC) was measured at the level of the cricothyroid membrane in a standing position. Waist circumference (WC) was measured midway between the lower rib and the iliac crest, and hip circumference at the level of the widest circumference over the great trochanters during upright position at the end of a gentle expiration. Pulse oximetry was used for measuring oxygen saturation $\left(\mathrm{SpO}_{2}\right)$ on room air at rest.

Spirometry was performed under the American Thoracic Society (ATS)/European Respiratory Society (ERS) standards (12). Forced expiratory volume in one second (FEV1), forced vital capacity (FVC) and FEV1/FVC values were obtained with the forced expiration curve. The severity of airway obstruction was based on the level of post-bronchodilator FEV1\% of the predicted value (10). The airway obstruction was classified as mild, intermediate, severe, and very severe according to cutoff values of FEV1 $80 \%, 50 \%$, and $30 \%$ respectively. All patients were questioned with the Epworth sleepiness scale (ESS) for detecting excessive daytime sleepiness (EDS), and the STOP-Bang for determining the risk of OSA. Both questionnaires were validated in Turkish $(13,14)$. EDS was defined when the total score was 10 or more on ESS. If the score was $\leq 2$ on the STOP-Bang questionnaire the risk for OSA was assumed as low. The patients with a score $>2$ were grouped as intermediate/high OSA risk.

\section{Statistical Analysis}

For the statistical evaluation, the Statistical Package for Social Sciences (SPSS) (IBM SPSS Inc., Chicago, IL) for Windows 23 was used. The distribution of data was evaluated by the Kolmogorov-Smirnov test. For random distribution, the median $\left[25^{\text {th }}\right.$ percentile (P25) and $75^{\text {th }}$ percentile (P75)] was displayed whereas mean \pm standart deviation was used for normal distribution. The results from qualitative data were shown as numbers and percentages. The Chi-Square test or Fisher Exact test was used to compare qualitative data. The Mann-Whitney U test (for random distribution) or independent sample T-test (for normal distribution) were executed for the comparisons between the groups of numerical variables. Correlations between numerical data were evaluated by Spearman correlation analysis, and the correlation between categorical variables was determined by the point biserial correlation. Multivariate regression analysis was used to determine the independent risk factors of the STOP-Bang survey risk score and Epworth Sleepiness Scale Score. Data with random distribution was emulated to a normal distribution with logarithmic transformation. Multivariate logistic regression analysis was used to determine the independent risk factors of OSA risk and daytime sleepiness. In statistical analysis, the $\mathrm{p}$-value $<0.05$ was considered significant.

\section{RESULTS}

The patients enrolled in the study $(\mathrm{n}=181)$ consist of 140 (77.3\%) males and 41 (22.7\%) females, aged between 40 75 years. The mean age of the patients was $62.1 \pm 8.8$ years, 
the average BMI level was $26.8 \pm 5.4 \mathrm{~kg} / \mathrm{m}^{2}$, and the average neck circumference was $40.6 \pm 3.5 \mathrm{~cm}$. It was determined that $32 \%(n=58)$ of the patients were active smokers and $49.2 \%(n=89)$ had quited smoking. The median smoking time was 40 packs/year. The median disease duration of the patients who applied to the outpatient clinic for COPD was 4 years. According to the combined COPD assessment, stated on GOLD 2019, 37\% $(n=67)$ of the patients were classified in the high-risk group (GOLD C and GOLD D) for exacerbation and symptom burden. As to spirometric grade, approximately half of the patients $(n=93,51.4 \%)$ had GOLD 3-4 grade of airflow limitation (FEV $1<50 \%)$. The presence of hypertension was declared by $30.4 \%(n=55)$ of patients and diabetes mellitus was declared by $11 \%(n=20)$ of the patients.

In our study, the ratio of patients with intermediate/high OSA risk was $69.6 \%(n=126)$. The median ESS score was 4 and the rate of EDS was found to be $30.4 \%(n=55)$.

As shown in Table 1, waist circumference and hip circumference measurements in this COPD population were also found to be significantly higher in the group with intermediate /high OSA risk $(\mathrm{p}<0.001)$. The rate of diabetes $(14.3 \%$ and $3.6 \%$; $=0.040)$, median ESS score (7.5 and 2, respectively; $\mathrm{p}<0.001$ ), and EDS ratio ( $42.1 \%$ and $3.6 \%$, respectively; $\mathrm{p}<0.001$ ) were found to be higher in patients with intermediate/high OSA risk when compared to patients with low OSA risk. Besides, $\mathrm{SpO}_{2} \quad(92.3 \pm 4.3$ and $94.2 \pm 2.3 ; \mathrm{p}<0.001)$ and $\mathrm{FVC}$ $(2,3 \pm 0.8$ and $2.6 \pm 0.8 ; \mathrm{p}=0.050)$ were significantly low in patients with intermediate/high OSA risk. However, the other clinical parameters including the mMRC scale, GOLD stages and exacerbation/hospitalization history did not differ significantly between OSA risk groups (Table 1).

The previous analysis indicated that waist circumference, hip circumference, FVC, $\mathrm{SpO}_{2}$, ESS score, and EDS could be possible risk factors associated with intermediate/ high OSA risk. In the multivariate logistic regression model in which these possible risk factors are included, $\mathrm{SpO}_{2}$ (OR: 0.83; $\mathrm{p}=0.007$ ) and ESS score $(\mathrm{OR}=1.28$; $\mathrm{p}<0.001)$ were determined as independent clinical factors affecting the intermediate// high level of OSA risk (Table 2 ).

\begin{tabular}{|c|c|c|c|c|}
\hline \multirow[b]{2}{*}{ Variables } & \multirow[b]{2}{*}{ OR } & \multicolumn{2}{|c|}{ 95\% CI } & \multirow[b]{2}{*}{ p } \\
\hline & & $\begin{array}{l}\text { Lower } \\
\text { limit }\end{array}$ & $\begin{array}{l}\text { Upper } \\
\text { limit }\end{array}$ & \\
\hline \multicolumn{5}{|c|}{ OSA risk (intermediate/high vs low) } \\
\hline $\mathrm{SpO}_{2}(\%)$ & 0.83 & 0.72 & 0.95 & 0.007 \\
\hline ESS & 1.28 & 1.16 & 1.41 & $<0.001$ \\
\hline \multicolumn{5}{|c|}{ Nagelkerke R2:0.331; $<<0.001$} \\
\hline
\end{tabular}

Table 1. Demographic and clinic parameters according to the OSA risk group

\begin{tabular}{|c|c|c|c|}
\hline \multirow[b]{2}{*}{ Parameters } & \multicolumn{2}{|c|}{ OSA Risk } & \multirow[b]{2}{*}{$\mathbf{p}$} \\
\hline & $\begin{array}{l}\text { Low } \\
(\mathrm{n}=55)\end{array}$ & $\begin{array}{l}\text { Intermediate/ } \\
\text { High }(n=126)\end{array}$ & \\
\hline Age (years) & $61.8 \pm 9.4$ & $62.3 \pm 8.6$ & 0.714 \\
\hline \multicolumn{4}{|l|}{ Gender, n (\%) } \\
\hline Male & $42(76.4)$ & $98(77.8)$ & \multirow{2}{*}{0.848} \\
\hline Female & $13(23.6)$ & $28(22.2)$ & \\
\hline BMI $\left(\mathrm{kg} / \mathrm{m}^{2}\right)$ & $24.8 \pm 3.8$ & $27.7 \pm 5.8$ & $<0.001$ \\
\hline Neck circumference $(\mathrm{cm})$ & $39.0 \pm 2,6$ & $41.2 \pm 3,6$ & $<0.001$ \\
\hline Waist circumference $(\mathrm{cm})$ & $93.0 \pm 9.7$ & $99.2 \pm 13.8$ & 0.001 \\
\hline Hip circumference $(\mathrm{cm})$ & $97.6 \pm 10$ & $104.6 \pm 12.9$ & $<0.001$ \\
\hline $\begin{array}{l}\text { Cigarette smoking } \\
\text { (pack/years) }\end{array}$ & $40(15-50)$ & $40(16-60)$ & 0.208 \\
\hline Never-smoked, n (\%) & $10(18.2)$ & $24(19.0)$ & \multirow{3}{*}{0.976} \\
\hline Quitted, n (\%) & $28(50.9)$ & $61(48.4)$ & \\
\hline Active-smoker, n (\%) & $17(30.9)$ & $41(32.5)$ & \\
\hline Comorbidities n (\%) & $6(10.9)$ & $62(49.2)$ & $<0.001$ \\
\hline HT n (\%) & $3(5.5)$ & $52(41.3)$ & $<0.001$ \\
\hline $\mathrm{DM}$ n $(\%)$ & $2(3.6)$ & $18(14.3)$ & 0.040 \\
\hline Duration of COPD & $4(0.5-9)$ & $4(1-10)$ & 0.365 \\
\hline \multicolumn{4}{|l|}{ PFT } \\
\hline FVC (L) & $2.6 \pm 0,8$ & $2.3 \pm 0,8$ & 0.050 \\
\hline FEV 1 (L) & $1.6 \pm 0.7$ & $1.4 \pm 0.6$ & 0.088 \\
\hline FVC, \% & $68.6 \pm 22.6$ & $62 \pm 16.2$ & 0.057 \\
\hline FEV $1, \%$ & $54.6 \pm 21.2$ & $49 \pm 15.6$ & 0.085 \\
\hline FEV1/FVC & $61.0 \pm 6.8$ & $60.8 \pm 8.3$ & 0.837 \\
\hline $\mathrm{SpO}_{2}, \%$ & $94.2 \pm 2.3$ & $92.3 \pm 4.3$ & $<0.001$ \\
\hline \multicolumn{4}{|l|}{ Airflow limitation, $\mathrm{n}(\%)$} \\
\hline GOLD1 (FEV1 $\geq 80 \%)$ & $6(10.9)$ & $7(5.6)$ & \multirow{4}{*}{0.430} \\
\hline $\begin{array}{l}\text { GOLD2 } \\
(50 \% \leq \mathrm{FEV} 1<79 \%)\end{array}$ & $25(45.5)$ & $50(39.7)$ & \\
\hline $\begin{array}{l}\text { GOLD3 } \\
(30 \% \leq \text { FEV } 1<\% 50 \%)\end{array}$ & $20(36.4)$ & $58(46.0)$ & \\
\hline GOLD4 (FEV1<30\%) & $4(7.3)$ & $11(8.7)$ & \\
\hline \multicolumn{4}{|l|}{ mMRC scale, n (\%) } \\
\hline $\mathrm{mMRC}<2$ & $20(36.4)$ & $34(27.0)$ & \multirow{2}{*}{0.220} \\
\hline $\mathrm{mMRC} \geq 2$ & $35(63.6)$ & $92(73.0)$ & \\
\hline \multicolumn{4}{|l|}{ GOLD 2019} \\
\hline A & $17(30.9)$ & $26(20.6)$ & 0.338 \\
\hline $\mathrm{B}$ & $22(40)$ & 49 (38.9) & \\
\hline $\mathrm{C}$ & $3(5.5)$ & $7(5.6)$ & \\
\hline $\mathrm{D}$ & $13(23.6)$ & $44(34.9)$ & \\
\hline $\begin{array}{l}\text { Exacerbations } \geq 2 / \text { past year, } \\
\mathrm{n}(\%)\end{array}$ & $14(25.5)$ & $46(36.5)$ & 0.171 \\
\hline $\begin{array}{l}\text { Hospitalizations } \geq 1 \text { past } \\
\text { year, } \mathrm{n}(\%)\end{array}$ & $5(9.1)$ & $19(15.1)$ & 0.345 \\
\hline $\begin{array}{l}\text { ICU admissions } \geq 1 \text { /past } \\
\text { year, } \mathrm{n}(\%)\end{array}$ & 0 & $4(3.2)$ & 0.432 \\
\hline ESS score & $2(0-4)$ & $7.5(3-11)$ & $<0.001$ \\
\hline EDS, n (\%) & $2(3.6)$ & $53(42.1)$ & $<0.001$ \\
\hline \multicolumn{4}{|c|}{$\begin{array}{l}\text { The results were shown as } n(\%) \text {, mean } \pm \text { standard deviation or median }\left(25^{\text {th }}-75^{\text {th }}\right. \\
\text { percentile) BMI: body-mass index, COPD: chronic obstructive pulmonary disease } \\
\text { DM: diabetes mellitus, EDS: excessive daytime sleepiness, ESS: Epworth sleepiness } \\
\text { scale, FEV1: Forced expiratory volume in one second, FVC: forced vital capacity, } \\
\text { GOLD: global initiative for chronic obstructive lung disease HT: hypertension, } \\
\text { ICU: intensive care unit, mMRC: modified medical research council, SpO } 2 \text { :Oxygen } \\
\text { saturation by pulse oximetry }\end{array}$} \\
\hline
\end{tabular}


Our results revealed that STOP-Bang score had an intermediate positive correlation with waist circumference $(\mathrm{r}=0.429 ; \mathrm{p}<0,001)$, hip circumference $(\mathrm{r}=0.409 ; \mathrm{p}<0.001)$ and ESS score $(\mathrm{r}=0.457 ; \mathrm{p}<0.001)$. The presence of DM, COPD duration, FVC(L), FEV1(L), $\mathrm{FVC} \%, \quad \mathrm{SpO}_{2}, \mathrm{GOLD} 2019 \mathrm{ABCD}$ staging, airway obstruction, and mMRC dyspnea scale showed a weak correlation with STOP-Bang score (Table 3). These factors associated with the STOP-Bang score were included in the multivariate linear regression model in which $\mathrm{SpO}_{2}(\beta \pm \mathrm{SH}:-0.09 \pm 0.03 ; \mathrm{p}=0.007)$ and $\log (\mathrm{ESS})$ ( $\beta \pm \mathrm{SH}: 0.14 \pm 0.02 ; \mathrm{p}<0.001)$ outshined as independent factors affecting the risk score (Table 4).

Table 3. The results of correlation analysis between STOP-Bang score and the demographical-clinical parameters

\begin{tabular}{|c|c|c|}
\hline \multirow{2}{*}{ Parameters } & \multicolumn{2}{|c|}{ STOP-Bang score } \\
\hline & $\mathbf{r}$ & $\mathbf{p}$ \\
\hline Age (years) & 0.083 & 0.268 \\
\hline Gender & 0.001 & 0.986 \\
\hline Waist circumference $(\mathrm{cm})$ & 0.429 & $<0.001$ \\
\hline Hip circumference $(\mathrm{cm})$ & 0.409 & $<0.001$ \\
\hline Cigarette smoking (pack/years) & 0.075 & 0.366 \\
\hline DM & 0.286 & $<0.001$ \\
\hline Duration of COPD & 0.178 & 0.017 \\
\hline FVC (L) & -0.184 & 0.014 \\
\hline FEV1(L) & -0.159 & 0.034 \\
\hline FVC(\%) & -0.173 & 0.020 \\
\hline FEV1(\%) & -0.138 & 0.065 \\
\hline FEV1/FVC & 0.049 & 0.517 \\
\hline $\mathrm{SpO}_{2}(\%)$ & -0.228 & 0.002 \\
\hline GOLD 2019 (ABCD stages) & 0.281 & $<0.001$ \\
\hline The severity of airflow limitation & 0.149 & 0.045 \\
\hline mMRC scale & 0.255 & 0.001 \\
\hline ESS score & 0.457 & $<0.001$ \\
\hline \multicolumn{3}{|c|}{$\begin{array}{l}\text { COPD: chronic obstructive pulmonary disease DM: diabetes mellitus, EDS: excessive } \\
\text { daytime sleepiness, ESS: Epworth sleepiness scale FEV1: Forced expiratory volume in } \\
\text { one second, FVC: forced vital capacity, GOLD: global initiative for chronic obstructive } \\
\text { lung disease, ICU: intensive care unit, mMRC: modified medical research council } \\
\text { SpO2: oxygen saturation by pulse oximetry }\end{array}$} \\
\hline
\end{tabular}

Table 4. Multivariate regression analysis for STOP-Bang score

\begin{tabular}{|c|c|c|c|c|}
\hline \multirow[b]{2}{*}{ Variables } & \multirow[b]{2}{*}{ OR } & \multicolumn{2}{|c|}{$\% 95 \mathrm{CI}$} & \multirow[b]{2}{*}{$\mathbf{p}$} \\
\hline & & $\begin{array}{l}\text { Lower } \\
\text { limit }\end{array}$ & $\begin{array}{l}\text { Upper } \\
\text { limit }\end{array}$ & \\
\hline Log (STOP-Bang score) & $\beta \pm S H$ & & & \\
\hline $\mathrm{SpO}_{2}(\%)$ & $-0.09 \pm 0.03$ & -0.16 & -0.03 & 0.007 \\
\hline \multirow[t]{2}{*}{$\log (\mathrm{ESS})$} & $0.14 \pm 0.02$ & 0.10 & 0.18 & $<0.001$ \\
\hline & \multicolumn{3}{|c|}{ R2: $0.285 ; \mathrm{p}<0.001$} & \\
\hline
\end{tabular}

CI: Confidence interval, ESS: Epworth sleepiness scale OR: Odds ratio, $\mathrm{SpO}_{2}$ : oxygen saturation by pulse oximetry, $\beta \pm \mathrm{SH}$ : regression coefficient \pm standard error

\section{DISCUSSION}

The overlap of OSA and COPD has some common factors affecting the pathophysiology and prognosis of each other. It is important to reveal the factors determining OSAS risk in COPD. The common factors such as age, gender, and smoking, may not provide clinical benefit in determining the probability of OSA. It may be speculated that especially advanced COPD with altered upper airway dynamics, respiratory pattern, and comorbidities may have different predictors from the general population (15). Approximately half of our study group consisted of COPD patients with mild/moderate airway obstruction and two-thirds of the population was with GOLD A-B representing the low-risk group for exacerbations. In this cohort of COPD patients, it was found that nearly $70 \%$ of the patients had moderate/high risk for OSA. OSA prevalence in COPD was reported between $2.9-66 \%$ in different studies $(2,16,17)$. Sharma et al. (18) reported the prevalence of high risk for OSA according to the Berlin Questionnaire as $55.2 \%$ in obstructive airway diseases. Oppositely, polysomnographic data of The Sleep Heart Health Study and Bednarek et al. (19) claimed no risk for mild obstruction (2). However, neither the degree of the airflow limitation nor the stage of COPD seemed to affect the OSA risk in our study group.

A recent study underlined that hypertension which is a component of the STOP-Bang questionnaire, could not be shown as an indicator of OSA in moderate to severe COPD. The authors recommended the interrogation of cardiovascular events, including stroke, myocardial infarction, or peripheral vascular disease for OSA risk (15). According to our results, the presence of diabetes may be a clue for the OSA-COPD overlap. Similarly, in the study of Steveling et al. (17) in which nocturnal polygraphy was used, the frequency of diabetes was higher in patients with the overlap syndrome.

The BMI threshold for the STOP-BANG is $>35 \mathrm{~kg} /$ $\mathrm{m}^{2}$ which is more than the average BMI $\left(26.8 \mathrm{~kg} / \mathrm{m}^{2}\right)$ of our study group. Although the average BMI of the intermediate/high-risk group was also found to be below the threshold, it is statistically higher than the low-risk group. On the other hand, the age threshold of 50 years might have increased the likelihood of high OSA risk in this elderly population with a mean age of 62.1 with male predominancy. But the gender distribution and mean age of the low-risk group were found to be statistically the same as the intermediate/high-risk group.

We showed that the ESS score correlates well with the OSA risk. However, it is known that the poor sleep quality in moderate/severe COPD obstacles the prediction of OSA with ESS $(15,16,20)$. The tiredness and daytime sleepiness may be attributed to either the poor sleep quality in COPD or the accompanying OSA. Eventually, the polysomnographic evaluation is needed for the differential diagnosis. We used the STOP-Bang questionnaire in this study because STOP-Bang was found to be associated with OSA in COPD (15). But our results must be confirmed with the polysomnographic data, the lack of which is the major limitation of this study. Schreiber et al. (21) 
published polysomnographic data from a pulmonary rehabilitation clinic comprising 190 COPD patients of whom $45 \%$ were diagnosed as moderate/severe OSAS. They also claimed that BMI and ESS may not be as reliable as in the general population for OSA risk assessment in a subgroup of patients with COPD.

In a Swiss cohort (17), BMI and smoking history were claimed as the only clinical predictors for OSA but other anthropometric parameters like the circumference of the neck, waist, or hip were not mentioned in this study. Contrary to the correlation between large neck circumference and OSA in the general population $(22,23)$, it is reported that advanced COPD patients with neck circumference $<42 \mathrm{~cm}$ are also prone to have OSA (15). The severity of OSA is particularly associated with abdominal obesity, and an increase of $13-15 \mathrm{~cm}$ around the waist or hip increases the risk of OSA 4 times (24). These findings are also compatible with the COPD cohort in the study of Turcani et al. (25). In our study, waist and hip circumference were found to be higher in the medium/high-risk OSA group compared to the low-risk OSA group.

The overlap of COPD-OSA may cause more profound nocturnal hypoxemia than those with OSA alone (4). According to the multivariate regression model; a lower percentage of oxygen saturation (OR: $0.83 ; \mathrm{p}=0.007)$ and higher ESS score $(\mathrm{OR}=1.28 ; \mathrm{p}<0.001)$ were determined as independent risk factors affecting the OSA risk and STOP-BANG questionnaire score. Our study pointed out that daytime $\mathrm{SpO}_{2}$ may be a possible Candidate for OSA risk assessment. In a study by Little et al. (26), it is stated that stable COPD patients with daytime arterial oxygen saturation of hemoglobin $\left(\mathrm{SaO}_{2}\right) \leq 93 \%$ are more likely to have nocturnal oxygen desaturation. In contrast to our results, STOP-BANG was not associated with ESS in a study involving advanced COPD patients. Milder COPD patients are likely to have fewer EDS related to respiratory insufficiency. It can be expected that a stagedependent relationship between ESS and OSA risk exists.

As to the limitations of the study, first, we could not perform polysomnography/polygraphy for the patients due to economic issues. However, the current recommendations that concern just the number of respiratory events for scoring PSG can also be insufficient to determine the real burden of breathing disorders during sleep for obstructive lung disease. The parameters including the duration of the respiratory events and the severity of the hypoxemia during sleep must be investigated for a better perception of OSACOPD overlap. Second, the data about the comorbidities were based on patients' declarations and previous prescriptions. Therefore, we could have some missing data due to memory factor and lack of objective tests for comorbidities.

\section{CONCLUSION}

In this study, it was revealed which clinical findings other than commonly used factors such as body-mass index can determine the intermediate/high OSA risk in COPD patients. Our results showed that low oxygen saturation, accompanying diabetes, high ESS score, and the high waist-hip circumference can be useful factors in differentiating patients with intermediate/high OSA risk in the COPD population. Furthermore, no difference in OSA risk was detected among all COPD stages according to GOLD. We suggest that all COPD patients should be questioned regardless of the stage in terms of OSA risk and the patients with the aforementioned characteristics should be directed to sleep clinics for polysomnography.

\section{ETHICAL DECLARATIONS}

Ethics Committee Approval: The study was approved by the Keçiören Training and Research Hospital Clinical Research Ethics Committee (Date: 11.09.2019, Decision No:2012-KAEK-15/1938).

Informed Consent: All patients signed the free and informed consent form for the usage of their data.

Referee Evaluation Process: Externally peer-reviewed.

Conflict of Interest Statement: The authors have no conflicts of interest to declare.

Financial Disclosure: The authors declared that this study has received no financial support.

Author Contributions: All of the authors declare that they have all participated in the design, execution, and analysis of the paper and that they have approved the final version

\section{REFERENCES}

1. McNicholas WT. Chronic obstructive pulmonary disease and obstructive sleep apnea: overlaps in pathophysiology, systemic inflammation, and cardiovascular disease. Am J Respir Crit Care Med 2009; 180: 692-700.

2. Sanders MH, Newman AB, Haggerty CL, et al. Sleep Heart Health Study. Sleep and sleep-disordered breathing in adults with predominantly mild obstructive airway disease. Am J Respir Crit Care Med 2003; 167: 7-14.

3. McNicholas WT. COPD-OSA Overlap syndrome: evolving evidence regarding epidemiology, clinical consequences, and management. Chest 2017; 152: 1318-26.

4. Collop N. Sleep and sleep disorders in chronic obstructive pulmonary disease. Respiration 2010; 80: 78-86.

5. Kim V, Han MK, Vance GB, et al. The chronic bronchitic phenotype of COPD: an analysis of the COPD gene study. Chest 2011; 140: 626-33.

6. Krachman SL, Tiwari R, Vega ME, et al. Effect of emphysema severity on the apnea-hypopnea index in smokers with obstructive sleep apnea. Ann Am Thorac Soc 2016; 13: 1129. 
7. Squier SB, Patil SP, Schneider H, Kirkness JP, Smith PL, Schwartz AR. Effect of end-expiratory lung volume on upper airway collapsibility in sleeping men and women. J Appl Physiol (1985) 2010; 109: 977-85.

8. Mermigkis C, Kopanakis A, Foldvary-Schaefer N, et al. Healthrelated quality of life in patients with obstructive sleep apnoea and chronic obstructive pulmonary disease (overlap syndrome). Int J Clin Pract 2007; 61: 207-11.

9. He B-T, Lu G, Xiao S-C, et al. Coexistence of OSA may compensate for sleep-related reduction in neural respiratory drive in patients with COPD. Thorax 2017; 72: 256-62.

10.Singh D, Agusti A, Anzueto A, et al. Global Strategy for the Diagnosis, Management, and Prevention of Chronic Obstructive Lung Disease: the GOLD science committee report 2019. Eur Respir J 2019; 53: 1900164.

11. Fletcher CM. Standardized questionnaire on respiratory symptoms: a statement prepared and approved by the MRC Committee on the Aetiology of Chronic Bronchitis (MRC breathlessness score). BMJ 1960; 2: 1662.

12. Graham BL, Steenbruggen I, Miller MR, et al. Standardization of Spirometry 2019 Update. An Official American Thoracic Society and European Respiratory Society Technical Statement. Am J Respir Crit Care Med 2019; 200: e70-e88.

13. Izci B, Ardic S, Firat $\mathrm{H}$, et al. Reliability and validity studies of the Turkish version of the Epworth Sleepiness Scale. Sleep Breath 2008; 12 : 161-8.

14. Acar HV, Kaya A, Yücel F, et al. Validation of the STOP-Bang questionnaire: An obstructive sleep apnoea screening tool in Turkish population. Turk J Anaesthesiol Reanim 2013; 41: 115-20.

15. Soler X, Liao SY, Marin JM, et al. Age, gender, neck circumference, and Epworth sleepiness scale do not predict obstructive sleep apnea (OSA) in moderate to severe chronic obstructive pulmonary disease (COPD): The challenge to predict OSA in advanced COPD. PLoS One 2017; 12: e0177289.

16. Soler X, Gaio E, Powell FL, et al. High Prevalence of Obstructive Sleep Apnea in Patients with Moderate to Severe Chronic Obstructive Pulmonary Disease. Ann Am Thorac Soc 2015; 12: 1219-25.

17.Steveling EH, Clarenbach CF, Miedinger D, et al. Predictors of the overlap syndrome and its association with comorbidities in patients with chronic obstructive pulmonary disease. Respiration 2014; 88: 451-7.

18. Sharma B, Feinsilver S, Owens RL, Malhotra A, McSharry D, Karbowitz S. Obstructive airway disease and obstructive sleep apnea: effect of pulmonary function. Lung 2011; 189: 37-41.

19. Bednarek M, Plywaczewski R, Jonczak L, Zielinski J. There is no relationship between chronic obstructive pulmonary disease and obstructive sleep apnea syndrome: a population study. Respiration 2005; 72: 142-9.

20. Price D, Small M, Milligan G, Higgins V, Gil EG, Estruch J. Impact of night-time symptoms in COPD: a real-world study in five European countries. Int J Chron Obstruct Pulmon Dis 2013; 8: 595-603.

21.Schreiber A, Cemmi F, Ambrosino N, Ceriana P, Lastoria C, Carlucci A. Prevalence and predictors of obstructive sleep apnea in patients with chronic obstructive pulmonary disease undergoing inpatient pulmonary rehabilitation. COPD 2018; 15: 3, 265-70.

22. Carmelli D, Swan GE, Bliwise DL. Relationship of 30-year changes in obesity to sleep-disordered breathing in the Western Collaborative Group Study. Obes Res 2000; 8: 632-7.

23. Stradling JR, Crosby JH. Predictors and prevalence of obstructive sleep apnoea and snoring in 1001 middle aged men. Thorax 1991; 46: 85-90.
24. Young T, Palta M, Dempsey J, Skatrud J, Weber S, Badr S. The occurrence of sleep-disordered breathing among middle-aged adults. N Engl J Med 1993; 328: 1230-5.

25.Turcani P, Skrickova J, Pavlik T, Janousova E, Orban M. The prevalence of obstructive sleep apnea in patients hospitalized for COPD exacerbation. Biomed Pap 2015; 159: 422-8.

26.Little SA, Elkholy MM, Chalmers GW, Farouk A, Patel KR, Thomson NC. Predictors of nocturnal oxygen desaturation in patients with COPD. Respir Med 1999; 93: 202-7. 